American Journal of Animal and Veterinary Sciences 2 (1): 6-10, 2007

ISSN 1557-4555

(C) 2007 Science Publications

\title{
Toll-Like Receptor (TLR) 2 and TLR4 Gene Expression in Canine Heart
}

\author{
${ }^{1}$ Linde, A., ${ }^{1}$ Blecha, F. and ${ }^{2}$ Melgarejo, T. \\ ${ }^{1}$ Departments of Anatomy and Physiology, and ${ }^{2}$ Human Nutrition, \\ Kansas State University, Manhattan, KS 66502, USA
}

\begin{abstract}
Toll-like receptors (TLRs) are archetypal pattern recognition receptors of immediate importance for an efficacious innate immune response. TLRs exhibit marked differential tissue activity and their levels within a discrete cell type can be highly dynamic. Of 13 known mammalian paralogues, three TLRs have been identified in the dog. Although cardiac TLR expression has been reported in other species, this study is the first to present evidence that these innate immune receptors are expressed in the canine heart. Heart tissue samples from all four chambers were collected from healthy dogs immediately after euthanasia and stored at $-80^{\circ} \mathrm{C}$ until analysis. Total RNA was extracted with TRI Regent. Specific primers were designed for amplification of canine TLR2 and TLR4 based on previously reported sequences for these genes. Reverse transcription was performed with M-MLV reverse transcriptase. PCR amplification was performed and PCR products analyzed by agarose gel electrophoresis. Bands were excised from the gel and the DNA isolated and cloned using the TA Cloning ${ }^{\circledR}$ Kit. The correct sequence for each product was verified by nucleotide sequencing. TLR4 expression was detected in the left ventricle and right atrium; TLR2 was detectable at low levels in the right atrium only. Identity of the RT-PCR products was confirmed by sequencing. Our findings show that at least two TLR paralogues - namely TLR2 and TLR4 are expressed in the canine heart. Additional studies are warranted to determine these immune receptors' potential implication in the development of naturally occurring heart disease in the dog.
\end{abstract}

Key words: Innate immunity, pattern recognition receptors, cardiac and dog

\section{INTRODUCTION}

Progress in the field of acquired immunity has historically overshadowed the field of immunology entirely ${ }^{[1]}$. More recent advances have, however, proven that innate defense mechanisms play key roles in a number of disease processes, and that several different so-called 'danger-signals' (infectious as well as noninfectious) may act as the trigger mechanism for an immune response ${ }^{[2]}$. Toll-like receptors (TLRs) are highly conserved classical pattern recognition receptors of the innate immune system, enabling the host to discriminate between pathogen associated molecular patterns (PAMPs) and self ${ }^{[1]}$. Detection of microbial components by TLRs also triggers activation of adaptive immunity, furthermore making this receptor family an important link between the two branches of the immune system ${ }^{[3,4]}$. The mammalian TLR family includes thirteen paralogues with differential tissue and cellular expression varying between species ${ }^{[1,3]}$. Different microbial patterns, such as lipopolysaccharide (LPS) from Gram-negative bacteria, lipotechoic acid (LTA) from Gram-positive bacteria and viral dsDNA, can act as ligands for different TLRs ${ }^{[1,3,5,6]}$. Following tissue damage, TLRs may also recognize certain host proteins, such as beta-defensins and heat shock proteins ${ }^{[1]}$. TLR-mediated signaling occurs through either a MyD88-dependent or MyD88-independent pathway, and it has been established that TLRs are complicit in not only immunological responses but also more general cellular homeostasis ${ }^{[1,5]}$. Toll-Like Receptor 4 (TLR4) was the first mammalian TLR identified, and it is consequently the best described of the family ${ }^{[3,7]}$. Information on TLRs in small animal species is still quite sparse. Recently, the full-length cDNA for TLR4 was cloned in dogs and cats ${ }^{[8]}$, and TLR2 expression has been identified in canine blood phagocytes ${ }^{[9]}$. Furthermore, the expression of TLR9 has been investigated in canine tissues ${ }^{[10]}$, and TLR expression has been reported in feline lymphoid tissues ${ }^{[1]}$. Additional studies have been conducted pertaining to TLR expression in other domestic animals, and TLRs have thus been identified in various organs of different species ${ }^{[12-17]}$. Increasing attention is paid to innate immunity and inflammation in heart disease and further identification of receptors and effector molecules of innate immunity is thus warranted. Virtually all cell types of the human and murine heart express TLRs ${ }^{[18]}$. TLR2-4, and TLR6 are readily detectable in cardiomyocytes ${ }^{[19,20]}$, while TLR16 are expressed on endotheliocytes, smooth muscle cells and macrophages of the vasculature ${ }^{[18]}$. A recent

Corresponding Author: Melgarejo, T., Dept Human Nutrition, Kansas State University, Manhattan, KS 66506-1407, USA Tel: +1 7855322730 
study suggests that mRNA expression of all ten human TLRs can be identified in the adult heart in people ${ }^{[21]}$. It has been suggested that endogenous signals, such as oxidative stress and heat shock proteins, can activate TLR-mediated signaling pathways in isolated ventricular cardiomyocytes ${ }^{[19]}$. Furthermore, the activation of myocardial TLR-mediated signaling pathways in response to exogenous ligands can induce cardiac dysfunction ${ }^{[22,23]}$. TLR2 has also been implicated in ventricular remodeling after myocardial infarction in mice ${ }^{[24]}$. No studies to date have reported on TLR expression in the canine heart. Since TLRs are essential signaling molecules governing an innate immune response, and because mediators of inflammation and innate immunity with increasing certainty are proven to play key roles in different types of cardiovascular diseases, we hypothesized that the normal canine heart expresses TLRs as a natural part of its intrinsic defense system. Here we show that TLR2 and TLR4 are expressed in whole heart homogenate from normal dogs. Further studies pertaining to TLR function and regulation in the canine heart are needed to establish the significance of these receptors in the heart of dogs in health and disease.

\section{MATERIALS \& METHODS}

Tissue preparation: Heart tissue samples were collected from healthy dogs immediately after euthanasia and snap-frozen in liquid nitrogen. Separate samples were obtained from both ventricles and atria. All animals were treated in strict accordance with university IACUC guidelines. Samples were temporarily stored at $-80^{\circ} \mathrm{C}$ until further analysis.

RNA extraction: Total RNA was extracted with TRI Regent (Sigma-Aldrich, St. Louis, MO) after grinding the frozen tissues in liquid nitrogen. Briefly, total RNA was treated with RQ1 RNase-free DNAse I (Promega, Madison, WI) to remove possible genomic DNA contamination.

Identification and cloning of TLR2 and TLR4 in the canine heart: To initiate our investigation of canine cardiac TLRs, specific primers were designed for amplification of canine TLR2 and TLR4 based on the previously reported sequences for these genes (GenBank No. NM_001005264 and NM 001002950). TLR2 forward and reverse primers sequences were $5^{\prime}$ ATGATTCCTACTGGGTGGAGAAC and 5'CGCAGCTTACAGAATCGCTG, respectively. TLR4 forward and reverse primers sequences were 5'CCTGGAAGGACTGTGCAATT and 5'TGCTTCAGTCTGGTTGTCCC, respectively.
Using the designed primers and total RNA (from each heart tissue section) as template, reverse transcription was performed with M-MLV (Moloney Murine Leukemia Virus) reverse transcriptase (Invitrogen, Carlsbad, CA) following the instructions of the manufacturer, in a $20-\mu 1$ reaction containing $500 \mathrm{ng}$ of total RNA and two-base anchored oligo(dT) primers $\left(5^{\prime}-(\mathrm{dT})_{14} \mathrm{VN}\right.$, where $\mathrm{N}$ is any base and $\mathrm{V}$ is $\mathrm{G}, \mathrm{A}$ or $\left.\mathrm{C}\right)$. The template cDNA $(1 \mu \mathrm{l})$ was amplified by PCR in a volume of $20 \mu \mathrm{l}$ containing $1 \mu \mathrm{M}$ of each primer and 2.5 units of Taq DNA polymerase (Promega). PCR amplification was performed by 35 cycles consisting of template denaturation $\left(94^{\circ} \mathrm{C}, 15 \mathrm{sec}\right)$, primer annealing $\left(55^{\circ} \mathrm{C}, 30 \mathrm{sec}\right)$ and polymerization $\left(72^{\circ} \mathrm{C}, 1 \mathrm{~min}\right)$. PCR products were analyzed by agarose gel electrophoresis. To confirm the specificity of the amplification products, bands were excised from the gel and the cDNA isolated and cloned using the TA Cloning ${ }^{\circledR}$ Kit (Invitrogen, Carlsbad, CA) and sequenced. Full cDNA sequences were compared with previously reported canine TLR2 and TLR4 sequences using the BLAST tool from the National Center of Biotechnology Information.

\section{RESULTS AND DISCUSSION}

Expression of TLR4 was detected in cardiac tissue samples originating from the left ventricle and right atrium; TLR2 expression was detectable at low levels in the right atrium only. No expression of either TLR2 or TLR4 was found either in the left atrium or right ventricle. Nucleotide sequences obtained from the RTPCR products were compared to previously described canine toll-like receptor nucleotide sequences and displayed complete homology. Tissue expression of TLR2 and TLR4 mRNA is shown in Fig. 1.

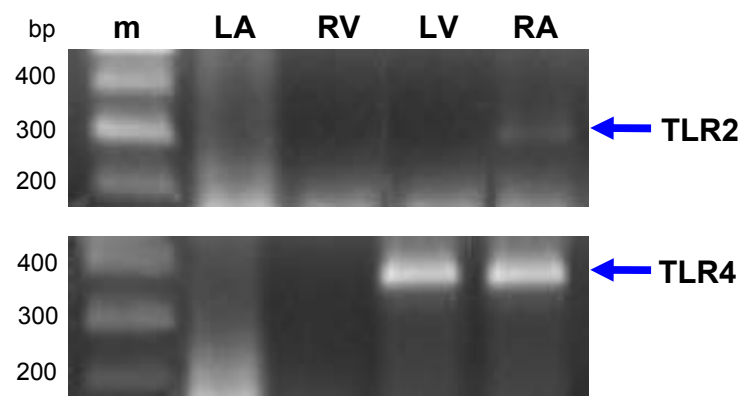

Fig. 1: Tissue expression of TLR2 and TLR4 mRNA. Total RNA (500 ng) was subjected to RT-PCR and $10 \quad 1$ of 35-cycle amplicons were separated on $2 \%$ agarose gel and stained with ethidium bromide. Top gel: TLR2, Bottom gel: TLR4. m: size markers; LA: left atrium, RV: right ventricle, LV: left ventricle, RA: right atrium. TLR2 and TLR4 amplicons (blue arrow) were 310 and 420 bp in size, respectively. 
Innate immunity and inflammation play central roles in a variety of pathologies - including common cardiovascular disorders, as shown in humans as well as rodent models ${ }^{[25]}$. It is likely that specific effector molecules and signaling pathways governing an innate immune response are of key importance to the development of certain types of naturally occurring heart diseases in dogs and other domestic animals. TLRs are an ancient pattern recognition system central for signaling in innate immunity ${ }^{[6]}$. TLR2 expression has been reported in canine blood phagocytes ${ }^{[9]}$, and TLR4 and TLR9 have been identified in selected dog tissues $^{[8,10,26]}$. To date, no study has reported on TLR expression in the dog heart. Knowledge of the expression pattern of these receptors in the normal canine heart is, however, of immediate importance for further mechanistic studies pertaining to innate immunity and the heart. The present work provides novel evidence that at least two TLRs - TLR2 and TLR4 - are expressed in the canine heart. We also report that TLR2 expression was detectable in the right atrium only, while TLR4 could be identified in the left ventricle as well as the right atrium. The global expression of TLRs changes secondary to intrinsic factors such as age, as well as cellular exposure to environmental stressors including pathogenic microorganisms ${ }^{[1]}$. Distinct TLRs may also affect each other's expression levels, and functional dimerization of certain TLRs has been reported ${ }^{[5]}$. A key design feature entails the trafficking of certain TLRs (TLR1-2 and TLR4-6) to the cell membrane thus allowing interaction with extracellular pathogens, while other TLRs (TLR3 and TLR7-9) are found virtually only at intracellular sites - this division, however, is not absolute ${ }^{[1]}$. The heart possesses a germ-line encoded innate stress system, which is activated in response to different types of injury ${ }^{[27]}$. Since TLRs are ancient germ-line encoded receptors of an innate immune response, and the right atrium the first location reached by blood entering the heart from the systemic circulation, it may be theorized that the expression of TLRs in this chamber is constitutive and possibly more diverse compared to other cardiac sites to allow early detection of noxae. Similarly, constitutive expression of TLR4 in the left ventricle would be advantageous as an intrinsic measure of detection situated immediately prior to blood leaving the heart and entering the main coronaries and systemic circulation. Bacterial LPS is the classical ligand for TLR4 activation (although other endogenous substances have been suggested as possible TLR4 stimulants also), whereas TLR2 recognizes a variety of microbial components, including LTA from Gram-positive bacteria $^{[3,6,28]}$. TLR2 has also been implicated as a mediator of staphylococcal induced cardiodepression by acting as a receptor for proinflammatory cytokines such as tumor necrosis factor (TNF) and interleukin- $1 \beta$ (IL$1 \beta$ ) (both of which are known contributors to cardiac decompensation in sepsis) ${ }^{[25]}$. In isolated coronary endothelial cells, TLR4 is required for LPS-signaling leading to an inflammatory response ${ }^{[29]}$. TLR4 is also a known contributor to development of chronic rejection after heart transplantation ${ }^{[30]}$. Interestingly, one study reports that cardiomyocytes and endotheliocytes have an equal amount of TLR4, but that only the latter responds to LPS, possibly making the need for cardiomyocytes as detectors obsolete ${ }^{[31]}$. However, TLR expression observed in cardiomyocytes may function as a back-up system that is activated after longer exposure to a pathogen or other noxia, thus serving as receptors in a "second line of defense" of an innate immune response. Further studies on the expression and function of TLRs within the frame work of an intrinsic cardiac immune response are needed as this may facilitate development of future novel treatment modalities in canine heart disease.

\section{ACKNOWLEDGEMENTS}

The authors wish to thank Dr. N. Sydney Moise, Cornell University, for kindly providing myocardial tissue samples for the study, and Shari Renaud-Farrell and Mary Ellen Charter for technical assistance with tissue collection. We also thank Alicia Jackson for technical assistance during preparation of the manuscript. The study was supported by COBRE/NIH grant P20 RR017686 (T.M.), and was presented in abstract-format at the American College of Veterinary Internal Medicine Forum 2006, Louisville, KY

\section{REFERENCES}

1. Hopkins, P. A., and S. Sriskandan. 2005. Mammalian Toll-like receptors: to immunity and beyond. Clin. Exp. Immunol. 140: 395-407.

2. Matzinger, P. 1994. Tolerance, danger, and the extended family. Annu. Rev. Immunol. 12: 9911045.

3. Takeda, K., T. Kaisho, and S. Akira. 2003. Tolllike receptors. Annu. Rev. Immunol. 21: 335-376.

4. Werling, D., and T. W. Jungi. 2003. TOLL-like receptors linking innate and adaptive immune response. Vet Immunol. Immunopathol. 91: 1-12.

5. Takeda, K., and S. Akira. 2004. TLR signaling pathways. Semin. Immunol. 16: 3-9. 
6. Takeda, K., and S. Akira. 2005. Toll-like receptors in innate immunity. Int Immunol. 17: 1-14.

7. Rock, F. L., G. Hardiman, J. C. Timans, R. A. Kastelein, and J. F. Bazan. 1998. A family of human receptors structurally related to Drosophila Toll. Proc. Natl. Acad. Sci. U. S. A 95: 588-593.

8. Asahina, Y., N. Yoshioka, R. Kano, T. Moritomo, and A. Hasegawa. 2003. Full-length cDNA cloning of Toll-like receptor 4 in dogs and cats. Vet Immunol. Immunopathol. 96: 159-167.

9. Bazzocchi, C., M. Mortarino, S. Comazzi, C. Bandi, A. Franceschi, and C. Genchi. 2005. Expression and function of Toll-like receptor 2 in canine blood phagocytes. Vet Immunol. Immunopathol. 104: 15-19.

10. Hashimoto, M., Y. Asahina, J. Sano, R. Kano, T. Moritomo, and A. Hasegawa. 2005. Cloning of canine toll-like receptor 9 and its expression in dog tissues. Vet Immunol. Immunopathol. 106: 159163.

11. Ignacio, G., S. Nordone, K. E. Howard, and G. A. Dean. 2005. Toll-like receptor expression in feline lymphoid tissues. Vet Immunol. Immunopathol. 106: 229-237.

12. Goldammer, T., H. Zerbe, A. Molenaar, H. J. Schuberth, R. M. Brunner, S. R. Kata, and H. M. Seyfert. 2004. Mastitis increases mammary mRNA abundance of beta-defensin 5, toll-like-receptor 2 (TLR2), and TLR4 but not TLR9 in cattle. Clin. Diagn. Lab Immunol. 11: 174-185.

13. Griebel, P. J., R. Brownlie, A. Manuja, A. Nichani, N. Mookherjee, Y. Popowych, G. Mutwiri, R. Hecker, and L. A. Babiuk. 2005. Bovine toll-like receptor 9: a comparative analysis of molecular structure, function and expression. Vet Immunol. Immunopathol. 108: 11-16.

14. Menzies, M., and A. Ingham. 2006. Identification and expression of Toll-like receptors 1-10 in selected bovine and ovine tissues. Vet Immunol. Immunopathol. 109: 23-30.

15. Shinkai, H., Y. Muneta, K. Suzuki, T. EguchiOgawa, T. Awata, and H. Uenishi. 2005. Porcine Toll-like receptor 1,6 , and 10 genes: Complete sequencing of genomic region and expression analysis. Mol Immunol. 43(9): 1474-1480.

16. Tohno, M., T. Shimosato, H. Kitazawa, S. Katoh, I. D. Iliev, T. Kimura, Y. Kawai, K. Watanabe, H. Aso, T. Yamaguchi, and T. Saito. 2005. Toll-like receptor 2 is expressed on the intestinal $\mathrm{M}$ cells in swine. Biochem. Biophys. Res. Commun. 330: 547-554.
17. White, S. N., S. R. Kata, and J. E. Womack. 2003. Comparative fine maps of bovine toll-like receptor 4 and toll-like receptor 2 regions. Mamm. Genome 14: 149-155.

18. Frantz, S., D. Fraccarollo, H. Wagner, T. M. Behr, P. Jung, C. E. Angermann, G. Ertl, and J. Bauersachs. 2003. Sustained activation of nuclear factor kappa B and activator protein 1 in chronic heart failure. Cardiovasc. Res. 57: 749-756.

19. Frantz, S., R. A. Kelly, and T. Bourcier. 2001. Role of TLR-2 in the activation of nuclear factor kappaB by oxidative stress in cardiac myocytes. J. Biol. Chem. 276: 5197-5203.

20. Knuefermann, P., S. Nemoto, G. Baumgarten, A. Misra, N. Sivasubramanian, B. A. Carabello, and J. G. Vallejo. 2002. Cardiac inflammation and innate immunity in septic shock: is there a role for tolllike receptors? Chest 121: 1329-1336.

21. Nishimura, M., and S. Naito. 2005. Tissue-specific mRNA expression profiles of human toll-like receptors and related genes. Biol Pharm. Bull. 28: 886-892.

22. Baumgarten G, Knuerferman P, Nozaki N, Sivasubramanian N, Mann DL, and Vallejo JG. 2001. In vivo expression of proinflammatory mediators in the adult heart after endotoxin administration: the role of toll-like receptor-4. J Infect Dis 1: 1617-1624.

23. Frantz, S., L. Kobzik, Y. D. Kim, R. Fukazawa, R. Medzhitov, R. T. Lee, and R. A. Kelly. 1999. Toll4 (TLR4) expression in cardiac myocytes in normal and failing myocardium. J Clin. Invest 104: 271280.

24. Shishido, T., N. Nozaki, S. Yamaguchi, Y. Shibata, J. Nitobe, T. Miyamoto, H. Takahashi, T. Arimoto, K. Maeda, M. Yamakawa, O. Takeuchi, S. Akira, Y. Takeishi, and I. Kubota. 2003. Toll-like receptor-2 modulates ventricular remodeling after myocardial infarction. Circulation 108: 2905-2910.

25. Knuefermann, P., J. Vallejo, and D. L. Mann. 2004. The role of innate immune responses in the heart in health and disease. Trends Cardiovasc. Med. 14: 1-7.

26. Wassef, A., K. Janardhan, J. W. Pearce, and B. Singh. 2004. Toll-like receptor 4 in normal and inflamed lungs and other organs of pig, dog and cattle. Histol. Histopathol. 19: 1201-1208.

27. Wilson, E. M., A. Diwan, F. G. Spinale, and D. L. Mann. 2004. Duality of innate stress responses in cardiac injury, repair, and remodeling. J Mol Cell Cardiol. 37: 801-811. 
28. Johnson, G. B., G. J. Brunn, and J. L. Platt. 2004. Cutting edge: an endogenous pathway to systemic inflammatory response syndrome (SIRS)-like reactions through Toll-like receptor 4. J Immunol. 172: 20-24.

29. Zeuke, S., A. J. Ulmer, S. Kusumoto, H. A. Katus, and H. Heine. 2002. TLR4-mediated inflammatory activation of human coronary artery endothelial cells by LPS. Cardiovasc. Res. 56: 126-134.
30. Methe, H., E. Zimmer, C. Grimm, M. Nabauer, and J. Koglin. 2004. Evidence for a role of toll-like receptor 4 in development of chronic allograft rejection after cardiac transplantation. Transplantation 78: 1324-1331.

31. Tavener, S. A., E. M. Long, S. M. Robbins, K. M. McRae, R. H. Van, and P. Kubes. 2004. Immune cell Toll-like receptor 4 is required for cardiac myocyte impairment during endotoxemia. Circ. Res. 95: 700-707. 